\title{
Investigation on the Natural Occurrence of Semicarbazide in Macrobrachium Nipponese prawns
}

\author{
Yun-hua Hui, Xuan Zhang, Hui-juan Yu* \\ Ministry of Agriculture Supervision and Testing Center for Aquatic Products;East China Sea Fisheries Research Institute;Chinese \\ Academy of Fishery Science;Shanghai 200090;China
}

\begin{abstract}
There is a suggestion that semicarbazide (SEM), the marker for the illegal veterinary nitrofurazone (NFZ), can naturally occur in some crustaceans. There were increasing occurrences that SEM had been found in Macrobrachium Nipponese (M. Nipponese) prawns during the routine quality controls testing for aquatic food in China since 2008. To ascertain the presence and source of SEM, samples were collected from different resources (i.e., aquatic product markets, natural waters, aquaculture farms) for qualitative and quantitative analysis of SEM. We incubated M. Nipponese larvae in the laboratory under control. The result showed that SEM was detected out in all the samples analyzed, including the wild-caught samples, and it presenting a regular content relationship among different parts of prawns (i.e., the shell $>$ head $>$ muscle). This relationship was unrelated to samples resources. In addition, a natural increase of SEM was observed after the larvae metamorphosing into postlarvae. These findings in M. Nipponense prawns provided new evidences for further confirming and researching the natural occurrence of SEM.
\end{abstract}

\section{Introduction}

Semicarbazide (SEM) is a member of hydrazine family of chemicals, which are known to possess carcinogenic potential[1-2]. SEM is also as the marker residue for detecting nitrofurazone (NFZ) in animal-derived food since 2003 in China, which is one of the nitrofuran antibiotics prohibited for use in food animals by the China issues Banned Drugs and Substances in Feed and Animal Production[3], because of the parent drugs are rapidly metabolized in vivo[4,5].The determination of the lowest detection limitation for the nitrofurans metabolite residues in animal-derived food is $1 \mu \mathrm{g} / \mathrm{kg}$ in Chinese current regulation[6], in accordance with the minimum required performance limit (MRPL) of $1 \mu \mathrm{g} / \mathrm{kg}$ by Commission Decision 2003/181/EC [7] within European Union.

The oriental river prawn (Macrobrachium Nipponese) belongs to the Macrobrachium species, and its native range comprising of China, Japan, Korea, Vietnam, Myanmar and Tai wan[8].This specie is a main economic prawn in China, as they feature rich resources across the East and South of China, and they can be bred exclusively in freshwater, and has highly nutritive value and aquaculture potential[9]. With the increase of cultivation and consumption of $\mathrm{M}$. Nipponese in China, more and more attention has been focused on the safety of the species. M. Nipponese has been listed on the monitoring objects of illegal veterinary drugs since $2007^{[10]}$. Thereafter, positive-SEM in many batches of M. Nipponese samples has been frequently detected during the routine quality controls testing for aquatic food during 2008-2011, which generally indicated the illegal use of NFZ. The occurrence of SEM in M. Nipponese samples has exerted a serious influence on aquatic marketing in China. This urges us to investigate the occurrence of SEM and its source in M Nipponese. Similar occurrence was also happened in Bangladesh from the winter of 2008 to the summer of 2009; The EU issued 54 nitrofuran-related warnings and rejected consignments of M. Rosenbergii from Bangladesh through the Rapid Alert
System for Food and Feed ${ }^{[11]}$, due to SEM was found in the export-oriented M. Rosenbergii prawns. Afterwards, McCracken et al. and Poucke et al. determined SEM in wild-caught M. Rosenbergii, and suggested that SEM naturally occurred in M. Rosenbergii, unrelated to the use of illegal drug ${ }^{[12-13]}$. However, the source of SEM occurred in crustaceans remains unclear. In addition, lacking of sufficient evidence, SEM is still used as the marker for the illegal veterinary drug NFZ by many countries.

In this study, we firstly employed LC- triple quadruple tandem mass spectrometer to determine SEM in different parts (muscle, shell and head) of $M$. Nipponese prawns, which were caught from different resources. Secondly, this study established a confirmation method by accurate-mass (HR/AM) Orbitrap mass spectrometer for reanalyzing the SEM in the wild-caught samples. Thirdly, the different forms (tissue-bound and total) of SEM in muscle of M. Nipponese prawns were analyzed. Finally, in the study, we were inquiring whether there would be an increase of SEM in prawns or not, with their development under laboratory condition. We studied the variation of the SEM concentration in artificially hatched $M$. Nipponese in the larva stage. We hope present work will provide valuable information for the research of SEM naturally occurring in crustaceans, as well as a new reference for strategic decision on whether SEM can continue to serve as the marker of the illegal veterinary drug NFZ or not for both domestic and overseas supervision departments of food quality and safety.

\section{Experimental}

\subsection{Reagents and Chemicals}

Methanol, ethyl acetate, hexane (n-hexane, 95\%) all were HPLC grade (J. T. Baker). 2-Nitrobenzaldehyde (2-NBA, 98\%) was bought from Alfa Aesar (Tianjin, China). Ammonium acetate (HPLC, 99.0\%) was from SigmaAldrich (St.Louis.MO.USA). Water $(18 \mathrm{M} \Omega)$ was 
obtained from a Milli-Q gradient A10 purifcation system (Millipore, France). All other chemicals were pro analysis grade or better.

Semicarbazide (SEM, 99.5\%) and Isotopically Labeled semicarbazide $\left({ }^{13} \mathrm{C},{ }^{15} \mathrm{~N}_{2}-\mathrm{SEM}, 99 \%\right)$ were purchased from Dr. Ehrenstorfer (Augsburg, Germany). Both of stock standard solutions of SEM and ${ }^{13} \mathrm{C},{ }^{15} \mathrm{~N}_{2}-$ SEM at $1 \mu \mathrm{g} / \mathrm{mL}$ were prepared by dissolving in methanol and stored at $4 \mathrm{C}$ in the dark. Work standard solutions were prepared by diluting the stock standard solutions in methanol to get the concentration of 200 $\mathrm{ng} / \mathrm{mL}$.

\subsection{Sampling work and sample treatment}

The M. Nipponense prawns were successively collected from Chinese natural waters (EastDongting Lake, SouthDongting Lake, Qiandao Lake, Weishan Lake, Shangdong reservoirs, Tianjing reservoirs), four aquaculture farms in different Chinese cities, and various aquatic product markets in Shanghai and Nanjing cities. Different parts (i.e., shell, muscle and head) of adult prawns were analyzed for the SEM, respectively. The weight of every batch of samples was up to $500 \mathrm{~g}$. Control samples were prepared by the blank Penaeus Vanmamei prawns from aquatic product market. All living prawns were transported to the laboratory and frozen at $-40^{\circ} \mathrm{C}$ for further treatment. The whole shell and the head which was removed the carapace were both shredded into pieces, separately. The muscle was minced in a food lender.

Along with the sampling work, we also collected feedstuffs samples and cultural water samples from every aquaculture farm and aquatic product market for detecting the illegal drug nitrofurazone. We caught sediment samples and water from culturing pond in every aquaculture farm and natural waters for detecting the SEM residue. All the pellet samples were shattered by shredder, and then were filtered through nylon filter, prepared for further analysis. The water samples were kept under the acid condition.

\subsection{Total and tissue-bound SEM extraction procedure}

For the determination of total SEM (free and tissuebound), internal standard ${ }^{13} \mathrm{C}^{15} \mathrm{~N}_{2}$-SEM was spiked at a concentration of $5 \mathrm{ng} / \mathrm{g}$ to every sample. The sample was hydrolyzed with $0.3 \mathrm{M} \mathrm{HCl}$ solution $(5 \mathrm{~mL}$ for muscle, 7 $\mathrm{mL}$ for shell) and was derivated by 2 -NBA $(150 \mu \mathrm{L}$, $100 \mathrm{mM}$ in dimethyl sulfoxide). The reaction mixture was kept at $37^{\circ} \mathrm{C}$ for $16 \mathrm{~h}$. After derivation reaction, the $\mathrm{pH}$ of the sample was adjusted between 7 and 7.5 with potassium phosphate, and then the sample was extracted with $8 \mathrm{~mL}$ of ethyl acetate. The supernatant was evaporated under nitrogen gas to dryness at $40 \mathrm{C}$. The dried residue was dissolved in $2 \mathrm{~mL}$ hexane solution and shaking for $10 \mathrm{~s}$, then added $1 \mathrm{~mL}$ methanol-water (5:95; $\mathrm{v} / \mathrm{v}$ ) and shaking for $1 \mathrm{~min}$. Afterwards, the mixture was centrifuged at $2500 \mathrm{rpm} / \mathrm{min}$ for $5 \mathrm{~min}$ and the subnatant (methanol-water) was filtered with $0.22 \mu \mathrm{m}$ filters, prepared for analysis by LC-MS/MS.

Tissue-bound SEM was determined using the method reported previously for the determination of nitrofuran metabolites $^{[14-15]}$. Shortly, $2 \pm 0.02 \mathrm{~g}$ of minced muscle was washed by a pre-extraction step with $8 \mathrm{~mL}$ of methanol-water $(50: 50 ; \mathrm{v} / \mathrm{v})$ and $8 \mathrm{~mL}$ of methanol-water $(75: 25 ; \mathrm{v} / \mathrm{v})$ to remove free SEM and then remainder samples were treated as described for total SEM.

For calculating the concentration present in the samples, blank $P$. Vanmamei samples were spiked with a series of standard SEM concentrations before extraction. The samples of this matrix-matched calibration curve were then analyzed.

\subsection{Determination for SEM by HPLC-Triple quanruple tandem mass spectrometer}

A triple quadrupole tandem mass spectrometer (TSQ Quantum ultra, Thermo Fisher Scientific, USA) was connected to an HPLC instrument (Thermo Fisher Scientific). The LC column was CAPCELL PAK $\mathrm{C}_{18}$ column $(2.0 \mathrm{~mm}$ i.d. $\times 100 \mathrm{~mm}, 5 \mu \mathrm{m})$ and was operated using a gradient mode. The composition of the mobile phase was a combination of two eluents A (methanol) and $\mathrm{B}(2 \mathrm{mM}$ ammonium acetate in water with $0.1 \%$ formic acid). The gradient profile started with $17 \% \mathrm{~A}$ for $2 \mathrm{~min}$ and increased to $85 \%$ for $6.5 \mathrm{~min}$ and then decreased to $17 \%$ for last $1.5 \mathrm{~min}$. The injection volume was $25 \mu \mathrm{L}$, a flow of $0.3 \mathrm{~mL} / \mathrm{min}$. The column temperature was maintained at $30^{\circ} \mathrm{C}$ throughout the analysis. This gradient profile gave acceptable resolution and reduced sample carry-over. Electrospray ionisation (ESI) was used as in positive ion mode. Spray voltage was set at $2.8 \mathrm{KV}$, capillary temperature at $320^{\circ} \mathrm{C}$, vaporizer temperature at $300^{\circ} \mathrm{C}$, shealth gas (N2) pressure at $10 \mathrm{psi}$, and aux gas $\left(\mathrm{N}_{2}\right)$ pressure at 5 psi. Collision pressure was set at 1.5 mTorr. Data were collected in the multiple reactions monitoring (MRM) mode in Table 1.

Table 1. The parent and product ions of SEM for MRM mode.

\begin{tabular}{cccc}
\hline Derivatives & Parent ion $(\mathrm{m} / \mathrm{z})$ & Product ions $(\mathrm{m} / \mathrm{z})$ & Collison energy $(\mathrm{eV})$ \\
\hline NPSEM & 209.0 & 192.0 (qualitative ion)/ 166.0 & $12 / 11$ \\
NPSEM- ${ }^{13} \mathrm{C}^{15} \mathrm{~N}$ & 212.0 & 168.0 & 11 \\
\hline
\end{tabular}




\subsection{Reconfirmatory analysis for SEM by Accurate-mass (AM) Orbitrap mass spectrometer}

Accurate-mass (AM) Orbitrap mass spectrometer features much higher resolution and enables the assigned masses of identified fragments with high accuracy ${ }^{[16]}$. Furthermore, Orbitrap mass spectrometer can eliminate interferences of geometric isomers or fragments with similar mass in coextraction substances that may result in negative results for confirming the target compounds ${ }^{[17-}$ ${ }^{19]}$.Samples were treated as described for total SEM. Detection was carried out using Q. Exactive benchtop LC-MS/MS (Thermo Fisher Scientific, USA) which combines high-performance quadrupole precursor selection with high resolution, accurate-mass (HR/AM) Orbitrap mass spectrometer. The LC column was Hypersil GOLDTM $\mathrm{C}_{18}$ column $(50 \mathrm{~mm} \times 2.1 \mathrm{~mm}$ I.D. $1.9 \mu \mathrm{m})$. The sheath gas was 35 units, and auxiliary gas was 10 units, capillary temperature was $320 \mathrm{C}$. The composition of the mobile phase was methanol/water. The gradient profile started with $30 \%$ methanol for $2 \mathrm{~min}$ and increased to $100 \%$ methanol at $2.01 \mathrm{~s}$ and ended with $30 \%$ methanol for last $2 \mathrm{~min}$. The total ion scan was at $\mathrm{m} / \mathrm{z}$ 150-500. Resolution Settings (FWHM) was set at 70000 (T-SIM) and $17500\left(\mathrm{ddms}^{2}\right)$, respectively.

\subsection{Animal experiment}

The carrying-egg prawns were bought from the professional aquafarm, where the whole culturing was under standard conditions of National Aquaculture Quality Safety Management Regulations ${ }^{[20]}$. The carrying-egg prawns were transported to the laboratory in net cages, and cultured in a cement pool $(2 \mathrm{~m} \times 7 \mathrm{~m} \times 0.8 \mathrm{~m})$. Temperature was kept at 25-27 C. Larvae were hatched out three days later, and the healthy and vigorous larvae were equally held in three aquariums with aerated, as three reduplicates. The larvae were fed with artificial diet (composed with milk powder, cod liver oil and hairtail muscle), soya-bean milk, commercialized spirulina power and artemia salina three times per day during their development. The aquariums were cleaned twice daily to remove excess feed and wastes. We collected the larvae samples at 1, 4, 6, 9, 12, 15 days after hatching from every aquarium for analyzing the total SEM. The $15^{\text {th }}$ day's larvae samples developed into postlarvae. All the inputs (i.e., feed and cultured water) were permitted to use after detectionof no residue of SEM or NFZ.

\section{Results and Discussions}

\subsection{Analysis for SEM}

HPLC-MS/MS was used for quantitative and qualitative analysis of SEM. The ions m/z 166 and m/z 192 were optimized. A linear response was gained by spiking blank Penaeus vanmamei muscle over the range of 0.5-500 $\mu \mathrm{g} / \mathrm{kg}$ of SEM standard (correlation $\mathrm{R}_{2}>0.9990$ ). Day-today variation was in an acceptable range (Coefficient of variation $6.4-12.3$ ). The recovery ranged from 80 to $112 \%$.
The limits of detection (LOD) and limits of quantitation (LOQ) were $0.5 \mu \mathrm{g} / \mathrm{kg}$ and $1 \mu \mathrm{g} / \mathrm{kg}$, respectively. According to qualitative rule by the European commission 2002/657/EC $\left.{ }^{[21}\right]$, namely the $\pm 2.5 \%$ tolerance for relative retention time of the analyte to that of the corresponding standard and observation of the tolerances set by EU criteria of peak area ratios from the controlled transitions reactions, all of the prawns analyzed by TSQ from different resources contained SEM, and every part (i.e., muscle, head and shell) was detected out SEM (Table 2).

Wild-caught prawns' samples were used to reanalysis of SEM by Orbitrap mass spectrometer. It was the first time for confirmation of SEM in biologicaltissues. Our study showed that it was a precise and reliable method for confirming the mass of compounds. The limit of detection (LOD) of $0.2 \mu \mathrm{g} / \mathrm{kg}$ for SEM by HR/AM with the higher resolution was gained. After the optimization of conditions by SEM standard $(1 \mu \mathrm{g} / \mathrm{mL})$, the results showed that the mass of parent ion at $\mathrm{m} / \mathrm{z}$ 209.06714 for $[\mathrm{M}+\mathrm{H}]+$ in selected ion monitoring ( $\mathrm{T}$ SIM) at $70000 \mathrm{FWHM}$, and the mass of the daughter ions at $\mathrm{m} / \mathrm{z} 192.04036$ and $\mathrm{m} / \mathrm{z} 166.06110$ in MS/MS of Isolated Ion Monitoring (ddms2) at 17500 FWHM. The mass accuracy of both parent and daughter ions was less than $2 \mathrm{ppm}$, that is, the mass incredible ranges of both parent and daughter ions were 209.06672-209.06756, 166.06076-166.06143 and192.03998-192.04074. The results showed that the parent ions of samples (209.06686-209.06721, $\Delta \mathrm{M}$ 0.24-1.82 ppm) and the daughter ions (166.06085-166.06123, $\Delta \mathrm{M} 0.18-1.51 \mathrm{ppm}$; 192.04006-192.04036, $\Delta \mathrm{M} 0.00-1.56 \mathrm{ppm}$ ) were both in the incredible range. The retention time and the ion mass/charge ratio were consistent with the SEM standard. The results of the re-analysis can further confirm the occurrence of SEM in wild-caught prawns.

The ranges of total SEM concentration in muscle of prawns were $3.17-21.34 \mu \mathrm{g} / \mathrm{kg}$ for wild-caught prawns, 2.30-7.92 $\mu \mathrm{g} / \mathrm{kg}$ for marketing prawns and 3.13$16.71 \mu \mathrm{g} / \mathrm{kg}$ for culturing prawns. The ranges of total SEM concentration in head of prawns were 28.59-93.64 $\mu \mathrm{g} / \mathrm{kg}$ for market-bought prawns, $53.54-113.67 \mu \mathrm{g} / \mathrm{kg}$ for wild-caught prawns and75.00-124.44 $\mu \mathrm{g} / \mathrm{kg}$ for cultured prawns. The ranges of SEM concentration in shell of prawns were $49.35-223.72 \mu \mathrm{g} / \mathrm{kg}$ for market-bought prawns, $46.62-287.08 \mu \mathrm{g} / \mathrm{kg}$ for wild-caught prawns and $232.61-370.41 \mu \mathrm{g} / \mathrm{kg}$ for cultured prawns.

Comparing the concentrations of total SEM in the three parts of prawns from different resources, a consistent relationship was observed; that was shell > head $>$ muscle (Table 3). It can conclude that SEM mostly distributes in the shell of M. Nipponense. This result is similar with the previous studies by Poucke et al. and McCraken et al., who both reported that SEM was mainly in the shell of $M$. Rosenbergii prawn ${ }^{5[12-13]}$, and the concentration was up to 100 times higher in the exoskeleton than that in the muscle ${ }^{[13]}$. 
Table 2. The result of qualitative analyses of SEM in the wild-caught M. Nipponese prawn

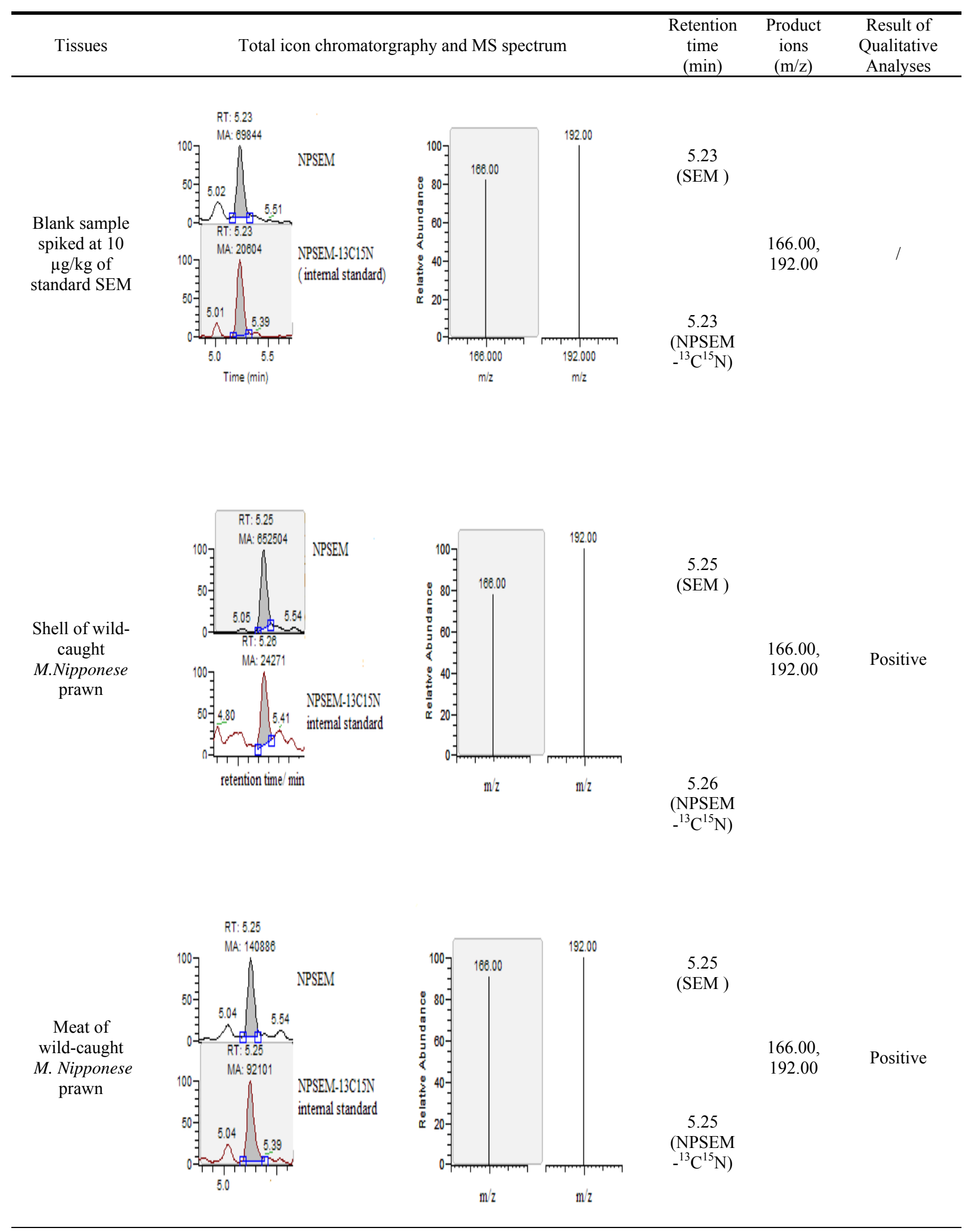




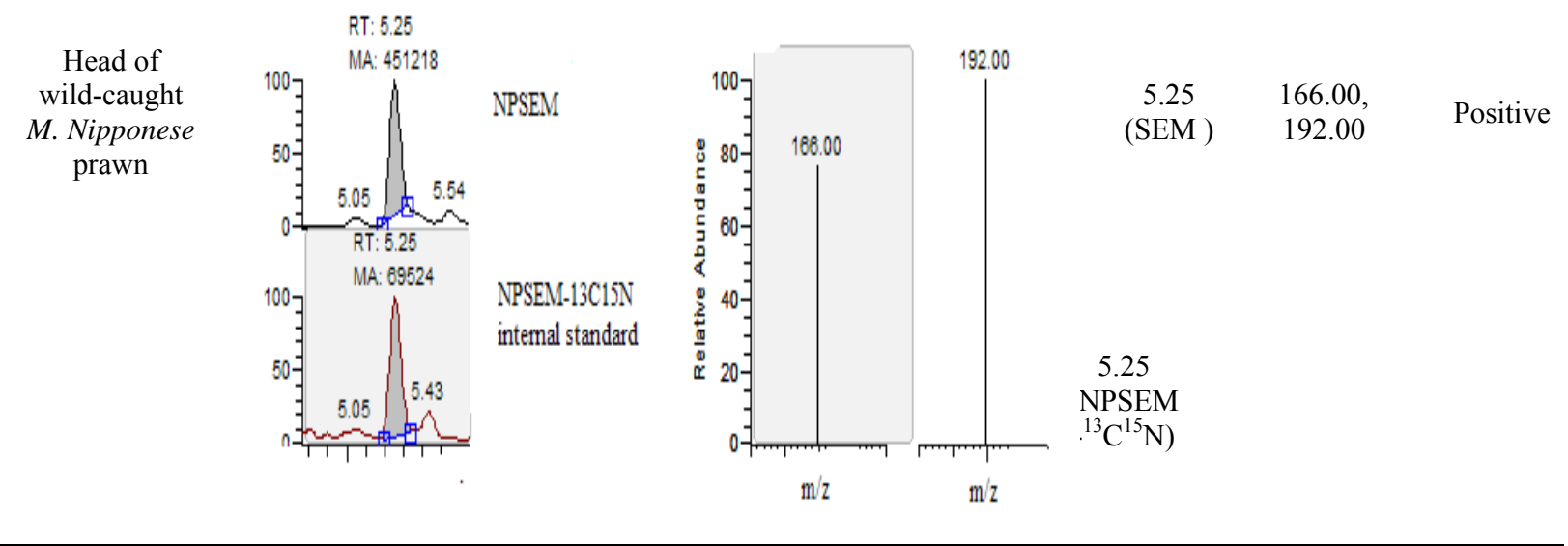

Table 3. The content distribution of total SEM in the M. Nipponese prawn from different resources.

\begin{tabular}{|c|c|c|c|}
\hline $\begin{array}{l}\text { Sample } \\
\text { resource }\end{array}$ & Aquatic product markets & Natural waters & Aquaculture farms \\
\hline
\end{tabular}
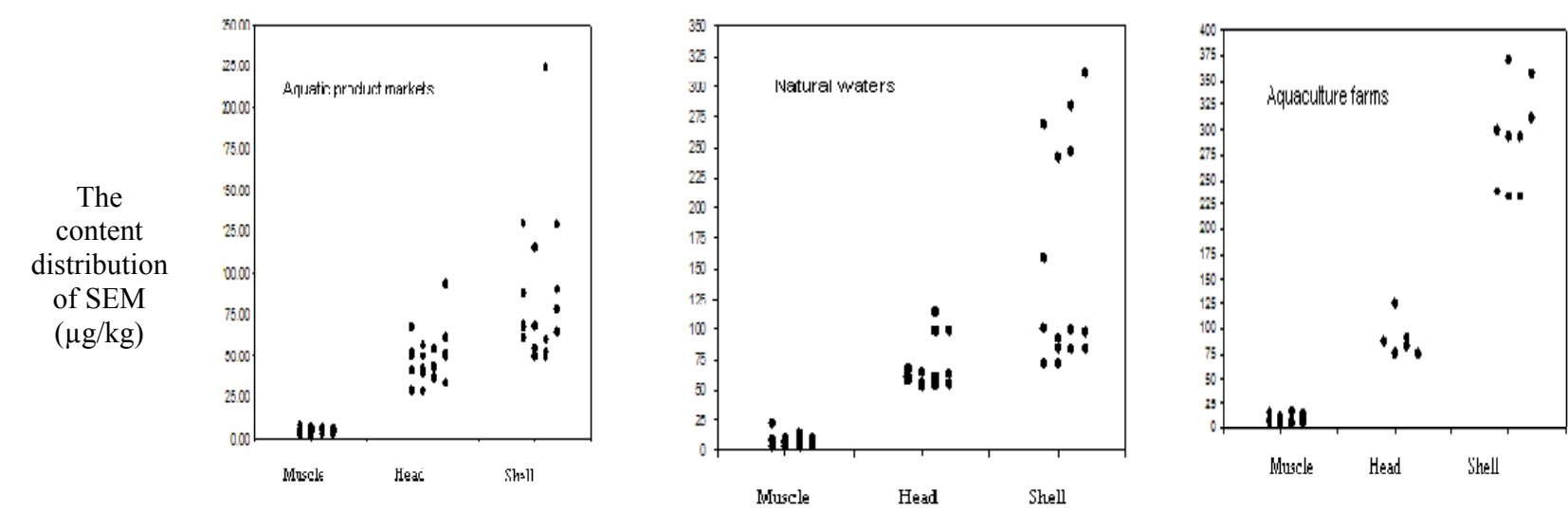

\subsection{Tissue-bound SEM in muscle of M.Nipponese}

was observed that total SEM in muscle ranged from 1.84$9.29 \mu \mathrm{g} / \mathrm{kg}$ and the tissue-bound SEM less than $1 \mu \mathrm{g} / \mathrm{kg}$ except for No.1, 2 and 8 samples (Table 4).

In this study, we have determined background levels of total and tissue-bound SEM in the muscle of 12 prawns. It

Table 4 the concentration of SEM in the muscle of $M$. Nipponese prawns.

\begin{tabular}{ccccccccccccc}
\hline Sample number & 1 & 2 & 3 & 4 & 5 & 6 & 7 & 8 & 9 & 10 & 11 & 12 \\
\hline Tissue-bound SEM $(\mu \mathrm{g} / \mathrm{kg})$ & 1.17 & 1.18 & $<0.5$ & 0.66 & 0.57 & 0.62 & $<0.5$ & 1.38 & $<0.5$ & $<0.5$ & $<0.5$ & 0.82 \\
Total SEM $(\mu \mathrm{g} / \mathrm{kg})$ & 7.95 & 9.29 & 4.03 & 3.25 & 6.25 & 2.5 & 3.15 & 3.13 & 2.34 & 2.22 & 1.84 & 5.94 \\
\hline
\end{tabular}

Note: $1-8$ collected from natural waters, $8 \sim 12$ collected from the aquatic product markets

The samples which contained less than $0.5 \mu \mathrm{g} / \mathrm{kg}$ tissue-bound SEM, were still confirmed as positive SEM. There was a phenomenon that increasing cases of positive SEM tests in freshwater M. Nipponense prawns in China, while not reported in other European countries yet. Based on the results in this study, that was a possible explanation for this discrepancy could be the fact that Chinese official laboratories employed the total SEM as the marker of related nitrofurazone-contaminate in the edible tissue (muscle) of prawns, while most European
Community Laboratories employed the tissue-bound SEM as the marker. However, there was more than $1 \mu \mathrm{g} / \mathrm{kg}$ (MPRL) of background level of tissue-bound SEM in two wild-caught prawns, which must not be related to the illegal NFZ abuse. Therefore, for $M$. Nipponense specie, taking the tissue-bound of SEM as the marker could also make false judgments for monitoring the use of illegal drug. 


\subsection{Investigation of the internal source of SEM in M. Nipponense}

In order to explore the natural occurrence of SEM in prawns, we investigated the developmental variation of SEM in the M. Nipponense prawns larva in the indoor laboratory. It was observed that SEM occurred in freshly hatched M. Nipponense larva with a level of $3.48 \pm 0.51$ $\mu \mathrm{g} / \mathrm{kg}$, and the level of SEM slightly decreased in the $4^{\text {th }}$ day after hatching and maintained this level until the $12^{\text {th }}$ and significantly increased to $14.6 \pm 1.36 \mu \mathrm{g} / \mathrm{kg}$ at $15^{\text {th }}$ day (Fig. 1).

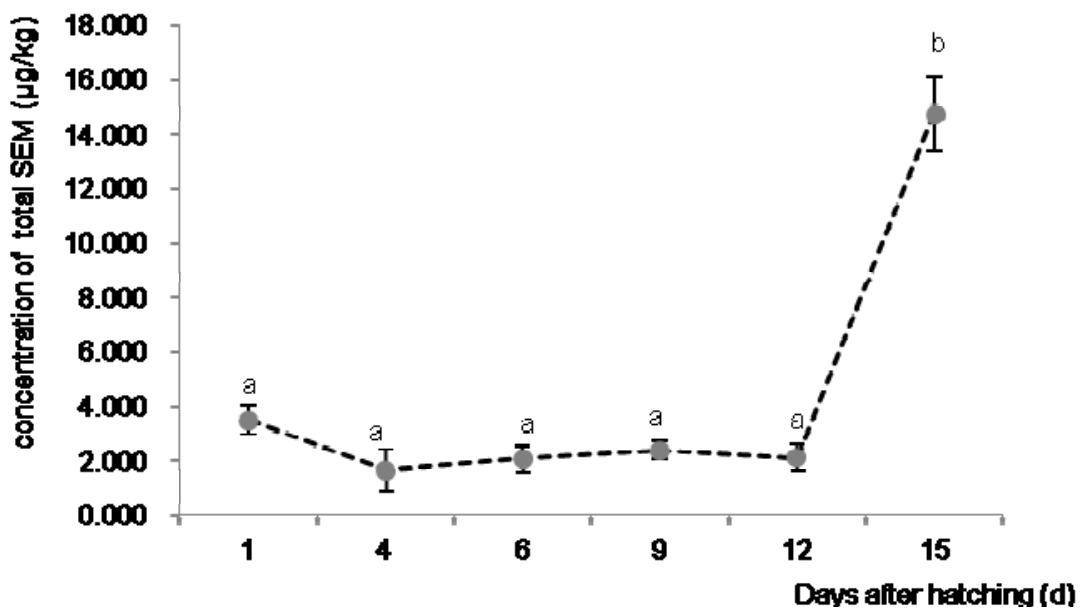

Figure1. Total SEM concentration in the M.Nipponese larva after hatching. Different letters indicate significant difference between different days after hatching.

This found of SEM in $M$. Nipponense larvae obviously had transmited from parent prawns. It was noted that artemia salina was one of the feeds during the experiment. Although we determined a very trace level of SEM in artemia salina, the level of SEM in prawns showed no significant change before the metamorphosing into postlarvae period (12d after hatching), while the level of SEM appeared a sudden increase nearly 7 times after metamorphosing (15 d after hatching).The sudden increase of SEM rather than a continuous increase was seemingly not associated with the feed of artemia salina. The larvae metamorphosed into postlarvae during the $12^{\text {th }}$ to $15^{\text {th }}$ day, meanwhile, SEM level in larva increased abruptly at $15^{\text {th }}$ day. The SEM suggestively has some connection with the metamorphosing development. Semicarbazide mainly distributed in the shell of $M$. Nipponense prawns, which has been demonstrated in this study. Poucke et al (2011), Kennedy et al (2011) and Yu et al (2012) suggested that semicarbazide was present as a natural component in shell of the $M$. Rosenbergii prawns tested ${ }^{[12-13,22]}$. Based on the current studies and previous reports, the increase of SEM observed in our study may be the result of natural shell development and shellrelated behaviors of the prawns after metamorphosing into postlarvae period.

\section{Conclusion}

Our study has observed the natural increase of semicarbazide during $M$. Nipponense's larva stage. It is the first time to clearly demonstrate SEM in $M$. Nipponense due to the internal source. This information can provide valuable information for further research on the natural occurrence of SEM in crustaceans. Moreover, the results of this study suggested that either the tissuebound SEM or total SEM would not be used as the marker of nitrofurazone any longer. An appropriate marker needs to be explored for monitoring nitrofurazone abuse. Whether the natural occurrence of SEM in crustaceans will exert a potential negative effect on human healthy or not, needs to be considered.

\section{Acknowledgement}

This study was supported by the research grant (No.1374) supported by agricultural products quality and safety supervision.

\section{References}

[1] Mori. K., Yasuno. A., Matsumoto. K., Induction of pulmonary tumors in mice with isonicotinic acid hydrazide, Gann. 1960, 51(1) 83-89.

[2] Parodi, S., De Flora. S., Cavanna. M., Pino. A., DNA-damaging activity in vivo and bacterial mutagenicity of sixteen hydrazine derivatives as related quantitatively to their carcinogenicity, Cancer Res. 1981, 41(2) 1469-1482.

[3] Announcement by the Ministry of Agriculture No.193, China.

[4] McCracken R. J., Blanchflower W. J., Rowan C., Determination of furazolidone in porcine tissue using thermosprayliquid chromatography-mass spectrometry and a study of the pharmacokineticsand stability of its residues. Analyst, 1995, 120, 23472351. 
[5] Nouws. J. F. M., Laurensen. J., Postmortal degradation of furazolidone andfuraltadone in edible tissues of calves, Veterinary Quarterly. 1990, 12, 5659.

[6] Announcement by the Ministry of Agriculture No.781, People's Republic of China.

[7] European Commission, Commission Decision 2003/181/EC. Off. J. Eur. Communities.

[8] Yu. H.P, Miyake. S., Five species of the genus Macrobrachium (Crustacea, Decapoda, Palaemonidae) from Taiwan, Ohmu. 1972, 3, 45-55.

[9] Cai. Y, Ng. P.K.L., The freshwater palaemonid prawns of Myanmar (Crustacea: Decapoda: Caridea). Hydrobiologia.2002, 487, 59-83.

[10] Veterinary Drug Residue Monitoring Sampling Plan in 2007 and Operational Measures of Residue Monitoring Sampling, Issued by Ministry of Agriculture, Administrative Regulations of the People's Republic of China on Veterinary Medicine, 2007, No.7.

[11].Information on http://ec.europa.eu/food/food/rapidalert/index_en.ht $\mathrm{m}$

[12]McCrackena. R., Hannab. B., Ennisa. D., The occurrence of semicarbazide in the muscle and shell of Bangladeshi fresh-water shrimp, Food Chem. 2011, 25, 1-6.

[13]Poucke C., Van. DE, Tavernier C., Investigation into the Possible Natural Occurrence of Semicarbazide in Macrobrachium rosenbergii Prawns, J. Agric. Food Chem.2011, 59, 2107-2112.

[14]Leitner. A., Zollner. P., Lindner. W., Determination of the metabolites of nitrofuran antibiotics in animal tissue by high-performance liquid chromatographytandem mass spectrometry. J. Chromatogr. 2001, 939 49-58.

[15]Cooper. K.M., Mulder. P.P., Rhijn. J.A. van., Depletion of four nitrofuran antibiotics and their tissue-bound metabolites in porcine tissues and determination using LC-MS/MS and HPLC-UV, Food Addit Contam. 2005, 22(5) 406-414.

[16]Hu. Q.Z., Noll. R. J., Li. H.Y., Makarov. A., The Orbitrap: a new mass spectrometer, J. Mass Spectrom. 2005, 40 430-443.

[17]Nielen M.W.F., Engelen M.C. van, Zuiderent R., Ramaker R., Screening and confirmation criteria for hormone residue analysis using liquid chromatography accurate mass time-of-flight, Fourier transform ion cyclotron resonance and orbitrap mass spectrometry techniques, Analytica Chimica Acta. 2007, 586(14) 122-129.

[18]Heeft E. van, Bolck.Y.J.C., Beumer. B., Full-Scan Accurate Mass Selectivity of Ultra-Performance Liquid Chromatography Combined with Time-ofFlight and Orbitrap Mass Spectrometry in Hormone and Veterinary Drug Residue Analysis, Journal of the American Society for Mass Spectrometry. 2009, 20(3) 451-463.

[19]Makarov. A, Scigelova. M., Coupling liquid chromatography to Orbitrap mass spectrometry, Journal of Chromatography A. 2010, 1217(25) 39383945.
[20] Announcement by the Ministry of Agriculture No.31, China.

[21]European Commission, Commission Decision 2002/657/EC. Off. J. Eur. Communities.

[22] Yu H. J., Li B., Cai Y. Q., Determination of Semicarbazide content in crustaceans by Liquid chromatography tandem mass spectrometry, Chinese Journal of Analytical Chemistry. 2012, 4(10) 15301535 . 